\title{
Representaciones de la inseguridad y violencia entre los habitantes del fraccionamiento Residencial Pinos del Norte, Merida Yucatán
}

\author{
Fredy Antonio Aguilar Canché*
}

\begin{abstract}
Resumen: Las siguientes líneas intentan plantear la importancia de los imaginarios urbanos como herramientas teóricas que permiten indagar en las representaciones sociales y espaciales de los pobladores del fraccionamiento Residencial Pinos del Norte de la ciudad de Mérida, Yucatán. En particular se centra en cómo un grupo de residentes de un espacio residencial privado construyen representaciones socioespaciales en torno a la seguridad fuera de su zona habitacional. Por último, se menciona el papel de la prensa como generador de imágenes e imaginarios que ayuda a consolidar los imaginarios del peligro.
\end{abstract} violencia.

Palabras clave: imaginario urbano, espacio residencial cerrado, inseguridad,

\section{Representations of insecurity and violence among the inhabitans of Residencial Pinos del Norte, Merida Yucatan's condominum}

\begin{abstract}
The following lines try to present the importance of urban imaginary as theoretical tools that permit to investigate in the spatial and social representations of the settlers of North Pines Residential close residence of the city of Mérida, Yucatan. Particularly, it centers on how a group of residents of a private urbanization build social and space representations about the security of their housing zone. Finally, there's a reference to the role the press as generator of images and imaginary which helps to consolidate the imaginary of danger.
\end{abstract}

Key words: urban imaginary, private urbanization, insecurity, violence.

Recibido: 23.06 .08

Aceptado: 21.07.08

\section{Introducción}

Hasta hace poco más de una década, el modo de cómo los sujetos piensan, representan e imaginan sus ciudades, era un campo poco explorado por las ciencias

*Universidad Autónoma de Yucatán. Mérida, México. Email: freddyaguilarcanche@ yahoo.com.mx 
sociales. Los actos, pensamientos y comportamientos individuales y colectivos en el ámbito urbano han llevado a sociólogos, psicólogos y antropólogos a interesarse cada vez más en este tipo de estudios. Ante ello, el concepto de imaginarios urbanos es una herramienta metodológica para analizar cómo las personas otorgan distintos significados a la ciudad, sus espacios y los sujetos con los que interactúan.

El concepto de imaginario urbano va más allá de ser una construcción mental ya que a través de ellos se puede comprender la organización de la sociedad de un determinado territorio, expresar las diferencias sociales, los deseos o temores relativos a los elementos socioespaciales de los sectores sociales que componen a dicha sociedad. De esta forma, constituye "una dimensión por medio de la cual, los distintos habitantes de una ciudad representan, significan y dan sentido a sus distintas prácticas cotidianas en el acto de habitar [...] una dimensión en la que se establecen distintas identidades y [...] se reconocen diferencias" (Nieto Calleja, 1998: 125)._Los imaginarios como representaciones sociales "llevan a la creencia continua e indeterminada de figuras, formas e imágenes de la ciudad. A través de ellos se busca aprender y comprender las características y atributos reales o irreales de la ciudad y la vida urbana calificando a personas y espacios urbanos como inseguro, sucio, monótono, opulento, miserable, indecente o peligroso.

Los imaginarios urbanos contienen características dinámicas con la capacidad de operar en las acciones y reelaborar la realidad social y las dimensiones de la cultura urbana (Aguilar, Nieto y Cinco 2001:165). Parte de esta realidad se concentra en fenómenos como la inseguridad y la violencia relacionados comúnmente como una amenaza a la integridad física y a las condiciones materiales de vida. Las diversas experiencias con estos fenómenos crean representaciones sobre los acontecimientos delictivos y sus ejecutores, constituyendo una verdadera malla que configura la vivencia de habitar la ciudad (Mandoky 1998). De esta forma, el imaginario goza de plena materialidad y un certificado de realidad ya que a los pobladores efectivamente los enfrentan diversos elementos y fenómenos que acontecen en el espacio geográfico en el que se desenvuelve el individuo y toman formas determinadas en función del estrato social al que pertenecen» (Ibíd.:210-211).

Durante el trabajo de campo para la tesis "Representaciones e imaginarios de la inseguridad y violencia urbana en la ciudad de Mérida Yucatán: la colonia San José Tecoh y el fraccionamiento Residencial Pinos del Norte", al indagar cuáles eran los espacios y personajes considerados como promotores de la violencia, los residentes de ambas zonas estudiadas conferían distintos significados a los elementos socioespaciales. Lo anterior permitía la elaboración de mapas subjetivos de una ciudad imaginada, su uso y la valoración de su zona de residencia frente a otras. A continuación, presento algunas de estas representaciones de los residentes del fraccionamiento Residencial Pinos del Norte. 


\section{Surgimiento y difusión de las residenciales en América Latina y la ciudad de Mérida Yucatán}

En los últimos años diversas ciudades del norte, centro y sur de América Latina han presentado una tendencia a la privatización del espacio urbano y la construcción de áreas cerradas para la vivienda. Durante la década de 1980, este fenómeno se gesta con notoria regularidad en diversos países en vías de desarrollo. Durante la década de 1990 este tipo de edificaciones se generaliza en ciudades como Argentina, Brasil, Chile y México (Véase trabajos como los desarrollados por Caldeira 2000, Svampa 2001, Carballo 2002, Rovira Pinto 2002, Hidalgo 2004, Cabrales y Canosa, 2002, Méndez y Rodríguez Chumillas, 2004), lo que ha llamado la atención de amplios sectores académicos quienes se han envuelto en un amplio debate acerca del surgimiento y consolidación de estos espacios en cada uno de los países antes mencionados.

Estos espacios cerrados también tienen diversas formas de nombrarse, como por ejemplo los casos presentados por Blakely y Snyder, (1999) en Estados Unidos y Roitman (2005) en Argentina, los nombran Gated Communities. Svampa (2001) por su parte denomina a estas áreas como Countries o barrios cerrados. Para el caso de Chile, Hidalgo (2004) le da el nombre de Ciudad Vallada. Caldeira (2000) en su estudio en Brasil, las llama Ciudad de Muros o Enclaves Fortificados. Para el caso de México, dichas zonas se nombran como fraccionamientos cerrados o bardeados (Cabrales y Canosa, 2001 y 2002, Giglia, 2002 y 2003, Méndez, 2002, Safa, 2002, López Leví y Rodríguez Chumillas, 2005). No obstante, el común denominador de estas formas residenciales es que son adoptadas por las clases medias altas y altas, quienes se repliegan en estas viviendas en un intento por optar a mayor seguridad, confort, alta calidad de vida y homogeneidad social.

Cabe destacar que la construcción de áreas cerradas para vivir no es un fenómeno de creación reciente, ${ }^{1}$ Janoschka y Glasze (2003) e Hidalgo (2004), en un intento por identificar la génesis de estas zonas habitacionales, proponen considerar algunas variables que sustentan la aparición de estos espacios residenciales. Entre las principales tesis están: 1) la globalización y transformación del espacio urbano, 2) el aumento de la criminalidad en la ciudad y 3) la promoción inmobiliaria y la búsqueda de distinción por parte de los grupos que acceden a los espacios residenciales cerrados. El surgimiento de estos espacios está asociado a diversas causas que pueden corresponder a cada uno de los puntos mencionados por separado, pero también el estar relacionadas entre si.

\footnotetext{
${ }^{1}$ Autores como Delumeau dan cuenta de ciudades cerradas en Europa en el siglo XVI, como un sistema de protección ante el temor generado por la inseguridad causada por la noche. Según Cabrales Barajas (2003) también se han documentado antecedentes de espacios cerrados en Estados Unidos desde el siglo XIX hasta la década de 1940.
} 


\section{Globalización y transformación en el espacio urbano}

La globalización ha jugado un papel sobresaliente en las transformaciones económicas y sociales de gran parte de las ciudades de América. El impacto de este fenómeno se ha traducido en oportunidades de desarrollo para gran número de ciudades latinoamericanas pero al mismo tiempo se ha presentado un proceso de dualización que incluye la fragmentación socio espacial de la ciudad, el cual ha sido señalado por Janoschka (2004) y Fuentes y Sierralta (2004). Según Da Mattos (2002 citado por Fuentes y Sierralta 2004), desde Argentina hasta México, se han presentado procesos de reestructuración económica a partir de los años 70's gracias al proceso constitutivo de la globalización. Las políticas neoliberales por las que han transitado algunos países latinoamericanos, han contribuido a la liberación del mercado del suelo que ha sido aprovechado por las inversiones privadas para la comercialización y promoción de espacios residenciales cerrados, orientado principalmente a las clases sociales con mayor poder adquisitivo.

\section{Aumento de la criminalidad en la ciudad}

La criminalidad ha sido una tesis para sustentar la aparición de los espacios residenciales cerrados en diversas ciudades (Valenzuela Aguilera 2003, Sáez Capel 2005, Lina Manjares 2004). Davis (1990) ha ofrecido interesantes referencias al fenómeno de las urbanizaciones cerradas en comunión con estos fenómenos. Este autor pone énfasis en el análisis del aumento de la criminalidad y los procesos de fragmentación en Los Ángeles, EE.UU durante la década de 1980. Esto generó una creciente privatización de los servicios públicos, incluidos la vivienda, para ciertos sectores de la sociedad que buscaban protegerse ante la perdida de seguridad tanto física como material. Por su parte, Caldeira (2000) hace referencia a la construcción de enclaves fortificados en la ciudad de Sao Paulo, Brasil. Su estudio pone en relieve la correlación entre la inseguridad y un nuevo tipo de patrón residencial que promueve una mayor segregación urbana. La criminalidad es uno de los factores que pueden incidir en la preferencia por estas viviendas, sin embargo, cabe señalar que la inseguridad ciudadana es variable en cada ciudad por lo que no todos los casos pueden generalizarse argumentando que la criminalidad da pie a la construcción de los espacios privados para la vivienda.

\section{Producción inmobiliaria, consumo y distinción}

Producto de un modelo urbano globalmente difundido (Janoschka y Glasze, 2003), las iniciativas realizadas por agentes inmobiliarios contribuyen a la aparición de mayor número y más variados tipos de residencias exclusivas de acuerdo al contexto urbano y la coyuntura social y económica en que se insertan. Las promotoras residenciales implementan diversas estrategias para consolidar en cada uno de los países en los que se promueven estos espacios, y generar su consumo. En el manejo de 
diferentes discursos publicitarios se exaltan imágenes como la exclusividad y la seguridad con el firme objetivo de captar compradores.

La oferta comercial de estas zonas ha generado un patrón de asentamiento sectorizado estableciendo con ello un tipo de segregación socio-espacial. La intención es agrupar a personas con capitales y consumos similares y propiciar una delimitación funcional del espacio, de las actividades y del contacto con aquellos ajenos a la zona residencial. Ante ello, estas urbanizaciones establecen una evidente diferenciación y separación mediante el empleo de bardas, sistemas de acceso controlado y otros dispositivos de control.

Adquirir una propiedad con las características antes mencionadas, establece una relación simbólica de inclusión/exclusión con aquellos que tienen o no acceso a estas viviendas (Gobantes, Peirano y Tapia 2005, Giglia 2002 y 2003). ${ }^{2}$ De acuerdo con Campos y García (2004 citado por Hidalgo 2004), residir en estas residencias va más allá del discurso acerca de la inseguridad y la violencia en la ciudad, y se puede analizar como una forma de consumo y de estatus que se asocia con la buena vida, seguridad y similitud socioeconómica.

\section{Los espacios residenciales cerrados en México}

Concuerdo con Cabrales y Canosa (2001) que a pesar de ser éste un tema relevante y actual de las ciudades de Latinoamérica, su estudio cada vez cobra mayor relevancia en México. Algunos autores han indagado los albores de las primeras unidades residenciales, entre ellos, el trabajo de Guerrien (s/f Internet) que señala que los primeros conjuntos habitacionales cerrados hicieron su aparición en los años 60's con la construcción de la Villa Olímpica en la ciudad de México. ${ }^{3}$ Por su parte Valverde (2003) menciona la construcción a principios de la década de los 70's, del fraccionamiento Club Campestre San Carlos, considerado como espacio exclusivo para la población de altos ingresos en las inmediaciones de Metepec en la ciudad de Toluca. Trabajos como los de Safa (2002) y Giglia (2002 y 2003) dan cuenta de los proyectos emprendidos en la Delegación Tlalplan, a finales de los años 1980. Es en este decenio que se presenta una mayor consolidación de este tipo de residencias en la ciudad y crece de manera gradual hasta los primeros años de la década de 1990.

Guadalajara también ha sido un lugar importante para el estudio del establecimiento y difusión de los fraccionamientos cerrados. Uno de los primeros

\footnotetext{
${ }^{2}$ La obra de Svampa (2001), Carballo (2002), Chevalier y Carballo (2005), para el caso argentino; Méndez, Rodríguez y López, (2005), Giglia $(2002,2003)$ para el caso en México, ofrecen referencias acerca de cómo los grupos medios y altos han comenzado a adoptar estas formas de consumo y de distinción.

${ }^{3}$ La construcción de este complejo fue para albergar a los atletas de todo el mundo participantes de la olimpiada de 1968.
} 
complejos habitacionales se cristalizó con el desarrollo de varias áreas residenciales cerradas a finales de los 60's y principios de los 70's. Su aparición fue estimulada por los procesos de expansión territorial del área urbana así como por el aumento demográfico propiciado por el flujo migratorio de las zonas rurales a la capital del estado. A partir de la segunda mitad de los años 80's en adelante, la zona metropolitana de esta ciudad fue incorporando fraccionamientos con características herméticas. Actualmente ha sido tan alta su aceptación que incluso su inicial direccionalidad a las clases altas ha cambiado para favorecer la ocupación de estas viviendas a las clases medias. Las ciudades fronterizas del norte de México no han sido la excepción, y trabajos como el de Méndez, Rodríguez y López (2005), López Leví y Rodríguez Chumillas (2005), dan cuenta de las unidades cerradas en Tijuana y la ciudad de Nogales Sonora respectivamente.

Para el caso de Mérida, Yucatán, el estudio de los fraccionamientos privados es prácticamente nulo. Los pocos acercamientos al tema han sido elaborados por antropólogos y arquitectos, quienes han señalado una serie de transformaciones económicas en el Estado a partir de los años 70's. Tal crecimiento económico implicó una estructuración del espacio en la ciudad de Mérida que trajo consigo la conformación de zonas a las cuales se les dotó con mayor infraestructura. En tal dinámica, una aparente segregación residencial se dio gracias a la aparición de espacios especializados y con mayores recursos urbanos propiciando un éxodo de personas con mediano y alto poder adquisitivo hacia las zonas residenciales cerradas.

De esta forma, estos complejos empiezan a emerger como una forma arquitectónica de mayor preferencia entre las clases medias altas y altas. Un ejemplo de lo anterior es el fraccionamiento Residencial Pinos del Norte, cuya construcción data aproximadamente del año 2000 según los primeros residentes de este lugar. Actualmente en el fraccionamiento Residencial Pinos del Norte conviven diversas personas con un perfil económico medio y alto. Como toda zona residencial, ésta utiliza diversos sistemas de protección para impedir el acceso de personas que no viven ahí. Sin embargo estas disposiciones sugeridas a los cuerpos de vigilancia contratada, así como los dispositivos para impedir el paso, son transgredidos, lo que provoca malestar entre los vecinos.

\section{Reconociendo al enemigo. Imaginarios y estereotipos de sujetos y espacios "peligrosos"}

Rodrigo Plá (2007) nos narra en su obra fílmica "La zona" cómo un grupo de residentes de la alta sociedad viven en un lugar fortificado, amurallado y vigilado ante la amenaza delictiva que ofrece el mundo exterior. No obstante, su aparente tranquilidad se convierte en paranoia cuando una de las murallas de protección se derrumba y logran penetrar un grupo de ladrones llevando a los vecinos del lugar a adoptar medidas de protección más allá de las imaginadas. No quisiera seguir comentando el resto del filme sino invitar al lector a pasar un rato de distracción y a la vez de reflexión con esta obra. 
Lo importante para lo que nos concierne es el hecho de cómo las personas de una zona residencial conforman sus representaciones de aquellos espacios y sujetos considerados como peligrosos.

Reguillo (1998) señala que las actividades ilícitas como el robo y la delincuencia se encuentran revestidos de un discurso que intenta señalar a los responsables. Entre ellos, se señalan a sujetos con ciertos atributos físicos o incluso fenotípicos como una forma de estigma que en términos de Goffman (1996) hace referencia a ciertas particularidades con una carga profundamente desacreditadora asociada espacialmente a algunos sujetos. Entre estos personajes se pueden mencionar a las prostitutas, drogadictos, jóvenes, delincuentes, inmigrantes, vagabundos, mendigos, homosexuales, extranjeros. A todos ellos se les reviste con características que contribuyen a construir y reafirmar estereotipos; discriminando, descalificando, segregando y restringiendo la relación con dichos sujetos.

Las representaciones encontradas en los discursos de los vecinos del fraccionamiento Residencial Pinos del Norte hacen referencia en un primer nivel a jóvenes. El vestuario, la forma de llevar el pelo, los tatuajes así como tener ciertos rasgos fenotípicos se convierten en distintivos que operan como clasificaciones de peligrosidad. Entre las principales agresiones que comúnmente se les imputan están las lesiones, el robo a vehículos, el vandalismo, daños a la propiedad y el homicidio. Frecuentemente el joven es visto como el principal promotor de la violencia y la inseguridad.

Otro nivel de representación del peligro es referido a la presencia de toda persona no residente del conjunto habitacional. Así, el agente externo adquiere una valoración negativa y se constituye como el "otro" aunque éste no necesariamente esté vinculado con actividades delictivas. Tal es el caso del jardinero, la trabajadora doméstica, los mensajeros, los agentes de publicidad y los predicadores. En el primer y segundo ejemplo, algunos de los vecinos del fraccionamiento contratan los servicios de personas para el arreglo del jardín o la casa. Los mensajeros ingresan mediante previa identificación y motivo de su visita, su presencia se debe al cobro de algún adeudo o entrega de cartas a las familias. Por último, hay familias pertenecientes a alguna congregación religiosa y, en ciertos casos, celebran reuniones con los miembros de su hermandad lo que también genera descontento.

A pesar de estas infracciones en el acceso, prevalecen los discursos que aluden a la poca o nula existencia de inseguridad y violencia dentro del fraccionamiento. El mayor grado de inseguridad y violencia se sitúa fuera del lugar de residencia. La idea de una comunidad aislada y autocontenida se rompe cotidianamente cuando los vecinos se trasladan fuera del complejo para realizar diversas actividades. Así, cada individuo amplía el mapa geográfico donde sitúa aquellos espacios o lugares donde se asienta con más fuerza la violencia urbana y la amenaza a la integridad física y material. Las calles, paraderos de autobuses, parques, plazas y canchas deportivas figuran como espacios inseguros y violentos. Comúnmente les atribuyen diversos significados y 
valoraciones negativas debido a sus características como por ejemplo el estar sucios, carentes de vigilancia y desprovistos de luz pública.

Las zonas habitacionales aledañas y los espacios públicos colindantes conforman los primeros ámbitos fuera de la residencial que representan mayor índice delictivo. Un ejemplo de ello es la colonia popular "Santa María de Chuburná" que se localiza alrededor del fraccionamiento y está conformada por familias de escasos recursos. Algunas de sus calles no cuentan con luz pública y vigilancia. Ante la falta de esta infraestructura pública, los vecinos de la zona residencial establecen en sus discursos una clara diferenciación con los espacios del exterior. Comentarios como "falta luz", o "asaltan" constituye un elemento de diferenciación social que se plasma en la distinción y localización de un área geográfica determinada.

Otro espacio aún más alejado del fraccionamiento es el Centro Histórico de la ciudad. ${ }^{4}$ Este último concentra la mayor oferta comercial en el área del mercado municipal, oficinas de administración pública, comercios y servicios, y reúne a gran cantidad de personas de diferentes lugares que se desplazan para desarrollar actividades laborales, consumir y adquirir productos básicos o para trasladarse hacia otros puntos de la ciudad. Sin embargo, algunas zonas, en especial las inmediaciones del mercado municipal, se encuentran con poca iluminación o no hay vigilancia policiaca, lo que genera constantes robos a los transeúntes a cualquier hora del día pero sobre todo por las noches. ${ }^{5}$ Los vecinos de la residencial frecuentan poco este lugar dadas las características por las que alimentan sus imaginarios, por lo que para abastecerse de diversos productos básicos optan por los supermercados más cercanos. Un elemento importante que refuerza el imaginario de éste y otros lugares, así como la caracterización de los sujetos peligrosos, lo presentan los discursos que genera la prensa meridana. Las imágenes y la información que transmiten los medios de comunicación sobre lugares y sujetos pueden conformar diversas representaciones a pesar de no experimentarse físicamente el (los) territorio(s).

\section{Violencia e inseguridad en el espacio meridano a través de la prensa}

La información de la prensa acerca de la incidencia delictiva en la ciudad hace posible la ubicación geográfica de las zonas que presentan mayores acontecimientos criminales. En Mérida, determinados sectores o áreas geográficas se constituyen como

\footnotetext{
${ }^{4}$ La distancia entre estos dos lugares es un poco más de 10 kilómetros.

${ }^{5}$ Estos datos fueron tomados de la información recabada para el proyecto Miedo, violencia, riesgo e inseguridad en el espacio público de Mérida iniciado por el Doctor José Fuente Gómez, así como para el proyecto de tesis. En ambos casos se registraron los reportes de asaltos y pandillerismo del año 2001 y 2004 respectivamente en la ciudad de Mérida. (Fuente: Diario de Yucatán y Por Esto!). En dichos estudios el centro histórico obtuvo un $32 \%$ del total de los delitos acontecidos en la ciudad.
} 
ejemplos de alta incidencia delictiva. La reiterada difusión de estas noticias conduce a la elaboración de imaginarios que afectan también a los pobladores que residen en dichos lugares. Identificar las zonas delictivas es también atribuirles características negativas a aquellos que viven en dichos distritos urbanos. Así, los pobladores de estos lugares son clasificados como violentos y son estereotipados como "los otros", ampliando la distancia social entre los ciudadanos de Mérida.

La prensa puede generar diferentes matrices de opinión y de representaciones en torno a las noticias que publican. Aguilar Díaz (1998) ya había señalado que la prensa proporciona el material para imaginar y valorar la ciudad al mismo tiempo que convoca al lector a relacionarse de forma mediada con los "otros" e incrementa las diferencias sociales y simbólicas ya presentes entre los ciudadanos. Leal por su parte mencionaba que "la difusión de los niveles altísimos de hechos delictivos, que atentan contra la vida y patrimonio de las personas, por parte de los medios de comunicación y sobre todo de la prensa escrita, es pieza esencial en el sentimiento de inseguridad existente en la ciudadanía" (Leal 1999:393). Así, los medios escritos refuerzan estereotipos latentes, y los mensajes difundidos por ellos influyen en las representaciones e imaginarios que el público se forma de una ciudad y en las formas en que se relacionan o dejan de relacionar con los espacios públicos y sujetos de su entorno que consideran de peligro.

\section{Reflexiones finales}

Las representaciones sobre la inseguridad y la violencia se han convertido en un operador simbólico que modifica el uso de la ciudad y la interacción con sus usuarios. El peligro real o imaginario acerca del crimen, crea diversos imaginarios sobre el espacio urbano y aquellos sujetos que lo habitan. Así, ciertos sectores sociales o áreas geográficas son señalados como ejemplos de la violencia e inseguridad urbana y pasan a ser estereotipados con atribuciones negativas. La identificación de figuras estereotipadas es posible gracias a las caracterizaciones que se hace de ellos a manera de prejuicios mediante componentes tomados de la realidad, pero también de la fantasía (Niño Murcia 2002).

En cuanto a la dimensión social, el joven es visto como el principal agente promotor de la violencia. El vestuario, la forma de llevar el pelo o los tatuajes se convierten en distintivos que operan como clasificaciones de peligrosidad. Las referencias hacia este grupo etáreo subrayan su vinculación con grupos de delincuentes y pandillas. Estas clasificaciones tienen un efecto social en el comportamiento y la interacción de los individuos con aquellos que poseen tales características.

De igual forma que con el grupo anterior, las proyecciones de la figura del delincuente entre los vecinos de la zona residencial tiene una presencia impersonal e instrumental por lo que puede ser atribuida a cualquier persona que genere 
desconfianza. En el plano discursivo, el delincuente no posee un rostro, sino que la figura del delincuente es referida a su mera existencia/presencia impersonal e instrumental" (Martín Barbero 2004: 301). Así, representaciones se concretizan en personajes que, de manera genérica, se erigen como especialmente peligrosos con aspectos polifacéticos.

En la dimensión espacial de las representaciones, cada sujeto mantiene un tipo de relación con los espacios de su ciudad. Esta interrelación hace posible la construcción de un amplio abanico de representaciones simbólicas sobre los espacios urbanos. Ello proporciona orientaciones a los habitantes de la ciudad y a su relación con ellos; sin embargo, no todos los lugares se encuentran simbolizados y constituyen lo mismo para los individuos, de tal forma que algunos de los espacios más que otros se erigen con atributos y significados.

Como he señalado, la frecuencia de las actividades delictivas, las experiencias concretas con estos sucesos, los relatos, vivencias y la información vertida por los medios de comunicación, conforman diversas representaciones e imaginarios que se reflejan en las formas en que las personas se relacionan con los espacios y sujetos de su entorno cercano y con el resto de la ciudad. Fenómenos como la inseguridad y la violencia se han constituido en "una de las preocupaciones principales en la agenda de todos los partidos políticos, de las ciencias sociales y de los ciudadanos comunes" (Adorno 1997:1) que no se definen exclusivamente por la realidad ofrecida por las cifras estadísticas, sino que también son ámbitos que se construyen socialmente. Desde esta óptica, analizar las representaciones e imaginarios de cada grupo social, nos ayuda a observar cómo cada uno de ellos realiza una construcción simbólica de la ciudad y de los sujetos que la habitan. 


\section{Bibliografía}

Adorno, Sergio (1997), La criminalidad violenta urbana en Brasil: tendencias y características presentado en el Seminario "El desafío de la violencia criminal urbana", BID, Río de Janeiro, 2-4 de marzo de 1997. Disponible en: http://ladb.unm.edu/aux/econ/ecosoc/1997/april/criminalidad.htm. Consultado el 20 de junio de 2008.

Aguilar Díaz Miguel (1998), "Espacio público prensa urbana" en Néstor García Canclini (coord.) Cultura y comunicación en la ciudad de México. La ciudad y los ciudadanos imaginados por los medios, Segunda parte, UAM-I/Grijalbo, México.

Aguilar Díaz Miguel, Nieto, Raúl y Cinco, Mónica (2001), "Ciudad de presencias: dimensiones evaluativas y sensoriales en las evocaciones de la ciudad de México" en: Abilio Vergara Figueroa (Coord.), 2001, Imaginarios: horizontes plurales, BUAP, México.

Blakely E. J. y Snyder M. G. (1999), Fortress America, Gated Communities In The United States, Brookings Institution Press/Lincoln Institute of Land Policy, Washington D.C./Cambridge, Mass.

Cabrales Barajas, Luis Felipe y Canosa Zamora, Elia (2001),'Segregación Residencial y fragmentación urbana: Los fraccionamientos cerrados en Guadalajara" en: Revista Espiral, Vol. 7, $\mathrm{N}^{\circ}$ 20, Universidad de Guadalajara, Guadalajara.

Idem (2002), "Nuevas formas y viejos Valores: Urbanizaciones cerradas de lujo en Guadalajara" en: Cabrales Barajas, Luis Felipe (coord.) Latinoamérica, países abiertos, ciudades cerradas, UNESCO- Universidad de Guadalajara, Guadalajara.

Caldeira, Teresa. (2000), City of Walls. Segregation and Citizenship in Sao Paulo, University of California Press.

Carballo, Cristina Teresa. (2002), "Buenos Aires y urbanización cerrada: nuevas formas de apropiación y fragmentación del espacio urbano", en: Cabrales Barajas, Luis Felipe (coord.) Latinoamérica, países abiertos, ciudades cerradas, UNESCO- Universidad de Guadalajara, Guadalajara.

Chevalier, Jacques y Carballo, Cristina (2005), Los espacios cerrados residenciales: en busca del entre-si. Estudio comparativo de entre el norte y el sur del continente americano. Ponencia presentada en el VII Coloquio Internacional de Geocrítica Los agentes urbanos y las políticas sobre la ciudad, Santiago de Chile.

Davis, Mike (1990), City of Quartz. Excavating the future of Los Angeles, Verso, New York. 
Fuentes, Luis y Sierralta, Carlos (2004), "Santiago de Chile, ¿ejemplo de una reestructuración capitalista global?”, en: Revista EURE vol. XXX, N91 Santiago de Chile.

Giglia, Ángela (2002), Privatización del espacio, auto segregación y participación ciudadana en la ciudad de México: el caso de las calles cerradas en la zona de Coapa (Tlalpan, Distrito Federal) disponible en: http://uamantropologia.info/web/articulos/giglia_art02.pdf

Idem (2003), "Espacio publico y espacios cerrados en la Ciudad de México", en P. Ramírez Kuri (coord.), Espacio público y reconstrucción de ciudadanía, FLACSO-Porrúa, México.

Gobantes Marin, Catalina, Peirano Olate, María Paz y Tapia Barría, Verónica (2005), Nuevos procesos de urbanización y transformaciones del barrio tradicional, ponencia presentada en el VII Coloquio Internacional de Geocrítica: Los agentes urbanos y las políticas sobre la ciudad, Santiago de Chile.

Goffman, Erving (1996), La identidad deteriorada, Amorrortu Editores, Barcelona.

Guerrien, Marc (s/f), Arquitectura de la inseguridad, percepción del crimen y fragmentación del espacio urbano en la zona metropolitana del valle de México. Disponible

en: http://halshs.ccsd.cnrs.fr/docs/00/05/40/63/PDF/Arquitectura_de_la_inseguridad.p df.

Hidalgo, Rodrigo (2004), "De los pequeños Condominios a la ciudad Vallada: Las urbanizaciones cerradas y la nueva geografía social en Santiago de Chile (19902000)" en: Revista EURE, Vol. 30, N 91, Santiago de Chile.

Janoschka, Michael (2004), El nuevo modelo de la ciudad Latinoamericana: fragmentación $\quad y \quad$ Privatización, disponible en: http://www.scielo.cl/scielo.php?script=sci_arttext\&pid=S0250-

71612002008500002

$\& \operatorname{lng}=$ es\&nrm=iso $>$. ISSN 0250-7161.

Janoschka, Michael y Glasze Georg (2003), “Urbanizaciones cerradas: un modelo analítico" en: Ciudades. Privatización de la ciudad. Revista de la RNIU, № 59, Puebla.

Leal Suárez, Luisa (1999), "El papel de los medios de comunicación en la construcción de las representaciones sociales en torno a la inseguridad ciudadana", en: Revista Espacios Abierto, Año/Vol. 8, № 003, Maracaibo.

Lina Manjares, Pedro (2004), Las puertas de la "microciudad" de México y la ecología del miedo, Ponencia presentada en el VII Coloquio Internacional de 
Geocrítica: Los agentes urbanos y las políticas sobre la ciudad, Santiago de Chile.

López Levi, Liliana y Rodríguez Chumillas, Isabel, (2005), Evidencias y discursos del miedo en la ciudad: casos mexicanos, Ponencia presentada en el VII Coloquio Internacional de Geocrítica: Los agentes urbanos y las políticas sobre la ciudad, Santiago de Chile.

Mandoky, Katia, (1998) "Desarraigo y quiebre de escalas en la Ciudad de México. Un problema de semiosis y estética urbana" en: Anuario de Espacios Urbanos, UAM- I México, Ciudad de México.

Martín Barbero, Jesús (2004), "Bogotá: los laberintos urbanos del miedo" en: Nava, Patricio y Zimmerman, Marc (coords.), Las ciudades Latinoamericanas en el nuevo [des] orden mundial, Siglo XIX, México.

Méndez, Eloy (2002), "Espacios de la simulació" en: Cabrales Barajas, Luis Felipe (coord.), Latinoamérica, países abiertos, ciudades cerradas, UNESCOUniversidad de Guadalajara, Guadalajara.

Méndez, Eloy y Rodríguez Chumillas, Isabel (2004), “Comunidades cercadas en la frontera México-EEUU”, en: Scripta Nova. Revista electrónica de Geografía y Ciencias Sociales, 2004, Vol. VIII, N 171.

Nieto Calleja, Raúl. (1998) «Lo imaginario como articulador de los órdenes laboral y urbano» en: Alteridades, Año 8, $\mathrm{N}^{\circ}$ 15, DCSyH/UAM-I, Ciudad de México.

Niño Murcia, Soledad (2002) "Eco del miedo en Santafé de Bogotá e imaginarios de sus ciudadanos", en Delumeau, Jean (comp.) El miedo. Reflexiones sobre su dimensión social y cultural, Corporación Región, Medellín.

Niño Murcia, Soledad y otros (1998), Territorios del miedo en Santa fe de Bogotá. Imaginarios de sus ciudadanos, Tercer Mundo Editores, Bogotá.

Reguillo Rossana (1998), Imaginarios globales, miedos locales la construcción social del miedo en la ciudad, Ponencia presentada en el IV Encuentro de la Asociación Latinoamericana de Investigadores de la Comunicación. ALAIC, Universidad Católica de Pernambuco, Recife.

Rovira Pinto, Adriano (2002), "Los barrios cerrados de Santiago de Chile: en busca de la seguridad y la privacidad perdidas", en: Cabrales Barajas, Luis Felipe (coord.) Latinoamérica, países abiertos, ciudades cerradas, UNESCOUniversidad de Guadalajara, Guadalajara.

Rovira P. Adriano, Salazar B. Alejandro y Álvarez C. Lili (2003), "Los condominios y urbanizaciones cerradas como nuevo modelo de construcción del espacio residencial en Santiago de Chile (1992-2000)", en: Scripta Nova. Revista electrónica de Geografía y Ciencias Sociales, Universidad de Barcelona, Vol. VII, 
$\mathrm{N}^{\circ} 146$.

Sáez Capel, José (2005), Las nuevas murallas de la ciudad y la invención del miedo: la sensación de ciudadana, ponencia presentada en el VII Coloquio Internacional de Geocrítica: Los agentes urbanos y las políticas sobre la ciudad, Santiago de Chile.

Safa Barraza, (2002), “Construir mundos, levantar muros y preservar patrimonios: condominios y fraccionamientos cerrados", en: Cabrales Barajas, Luis Felipe (coord.) Latinoamérica, países abiertos, ciudades cerradas, UNESCOUniversidad de Guadalajara, Guadalajara.

Svampa, Maristella (2001), Los que ganaron. La vida en los Countries y barrios privados, Editorial Biblos, Buenos Aires.

Valenzuela Aguilera, Alfonso (2003), "Límites, segregación y control social del espacio", en: Ciudades, № 59, Revista de la RNIU, Puebla.

Valverde, Carmen (2003), "Un proceso de difusión: urbanizaciones cerradas", en: Ciudades, $\mathrm{N}^{\circ} 59$, Revista de la RNIU, Puebla.

\section{Filmografía}

Plá, Rodrigo (2007), “La Zona”, Alta Films, España- México. 